\title{
Dynamics of biodegradable DOC produced by freshwater plankton communities
}

\author{
Morten Søndergaard ${ }^{1, *}$, Niels Henrik Borch ${ }^{1}$, Bo Riemann $^{2}$ \\ ${ }^{1}$ Freshwater Biological Laboratory, University of Copenhagen, Helsingørsgade 51, 3400 Hillerød, Denmark \\ ${ }^{2}$ National Environmental Research Laboratory, Department of Marine Ecology, PB 385, 4000 Roskilde, Denmark
}

\begin{abstract}
The net production of dissolved organic carbon (DOC) and DOC biodegradability were followed during experimental diatom blooms in freshwater enclosures. DOC accumulated at almost constant rates of $4.4 \mu \mathrm{M} \mathrm{d}^{-1}$ during the increase and the decay of the blooms. A high production of $188 \mu \mathrm{M}$ occurred in an episodic event over $5 \mathrm{~d}$ in 1 of 4 enclosures. Two independent methods to measure biodegradable DOC (BDOC) showed perfect agreement and inorganic nutrients neither affected the degradation rates nor the amount of DOC degraded. The accumulating DOC was initially recalcitrant (RDOC) and about $25 \mu \mathrm{M}$ RDOC was produced during the increase in phytoplankton biomass. When the plankton communities declined, the BDOC increased, concomitant with the continued DOC accumulation: about 60 to $82 \%$ of the new DOC was biodegradable when the experiment was terminated after $19 \mathrm{~d}$. It is suggested that a change in the quality of produced DOC took place over the course of the bloom. The turnover time of the BDOC pool was measured in batch cultures and ranged from 75 to $120 \mathrm{~d}$. The biodegradable pool was totally dominated by semi-labile components. The high chemical resistance to degradation controls the long turnover times and the accumulation of DOC.
\end{abstract}

KEY WORDS: Biodegradable DOC $\cdot$ Phytoplankton blooms $\cdot$ Lakes

\section{INTRODUCTION}

The standing stock of dissolved organic carbon (DOC) is the largest pool of organic carbon in the oceans and in most lakes (Birge \& Juday 1934, Sharp 1973). A relatively high concentration of recalcitrant DOC and the intimate coupling between the production and bacterial assimilation of DOC results in rather invariate DOC concentrations compared with the seasonal dynamics of particulate matter. Despite the efficient bacterial scavenging of DOC, measurements of DOC in oceans have shown accumulation of newly produced DOC over the productive season in quantities surpassing the accumulation of particulate organic carbon (POC) (Carlson et al. 1994, Børsheim \& Myklestad 1997, reviewed by Williams 1995). Accumulation of DOC is normally compared with the concentra-

*E-mail: msondergaard@zi.ku.dk tions of DOC during winter mixing or alternatively with the concentration of DOC in deep ocean water. Thus, new DOC is of autochthonous origin and accumulates over the growing season. Although bacterial nutrient limitation could lead to accumulation of otherwise biodegradable DOC (BDOC) (Thingstad \& Lignell 1997), there is a growing body of evidence that it is the resistance to microbial attack, i.e. the semi-labile nature, that is controlling the seasonal and episodic accumulations of DOC in marine systems (Ittekkot et al. 1981, Eberlein et al. 1983, Carlson et al. 1998, Søndergaard et al. 2000).

Temporal DOC variations in lakes have often been observed (Allen 1969, Ochiai et al. 1979, Søndergaard et al. 1995, Weiss \& Simon 1999), but few studies can be used to analyse the accumulation of autochthonous DOC due to influx of terrestrial organic matter, mixing events and sediment contact. The study by Ochiai et al. (1979) is one example that qualifies for analysis. In a 
eutrophic Japanese lake they measured an epilimnetic increase of $121 \mu \mathrm{M}$ DOC over $45 \mathrm{~d}$. The increase cooccurred with the growth and decline of a Fragillaria spring bloom and DOC increased at an almost constant rate of $2.7 \mathrm{\mu M} \mathrm{d}^{-1}$ (Ochiai et al. 1979). Dissolved combined carbohydrates explained about $33 \%$ of the DOC increase. Decomposition experiments showed that the carbohydrates were utilised by bacteria and had a turnover time of about $20 \mathrm{~d}$.

The DOC pool consists of a small labile pool with short turnover times (hours, days), a semi- labile pool with longer turnover times (weeks, months) and a recalcitrant background. Ogura (1975) used an exponential decay model with 2 or 3 decay coefficients to describe DOC degradation measured within a time-frame of about $50 \mathrm{~d}$. Most recent studies on the degradation of DOC have been short-term, with incubations lasting from 3 to $14 \mathrm{~d}$ (Søndergaard \& Middelboe 1995). Only DOC with short turnover times can be detected during these incubations, and organic species with long turnover times, but still biodegradable, would partly escape detection. The study by Fry et al. (1996) showed that a major part of the DOC produced during the decay of an experimental diatom bloom was semi-labile with turnover times counted in weeks and, furthermore, that 25 to $30 \%$ of the bloom-derived DOC was not biologically degraded after 2.5 yr. DOC produced by different marine plankton communities - nutrient replete and declining - was also shown to have turnover times of several weeks (Søndergaard et al. 2000).

The relative amount of BDOC in lakes has a median value of $14 \%$ of total DOC (Søndergaard \& Middelboe 1995). The variability of BDOC is, however, rather large and ranges from about 5 to $53 \%$ of the total DOC pool (Søndergaard 1984, Søndergaard \& Borch 1992, Tranvik \& Jørgensen 1995, Weiss \& Simon 1999). The higher values are suggested to relate to bloom events and to signify a temporal uncoupling of DOC production and utilisation. The ecological consequences of a temporal uncoupling of DOC production and degradation due to the production of semi-labile DOC are that microbial activity and regeneration of nutrients are not intimately linked with primary production.

It was the purpose of the present investigation to study the autochthonous production and biodegradability of DOC produced during experimental fresh water phytoplankton blooms. We hypothesised (1) that DOC accumulates during the development and decay of a phytoplankton bloom and (2) that the accumulation is controlled by the production of either recalcitrant and/or semi-labile DOC with long turnover times. Two independent methods were used to measure BDOC. The study showed a net production of DOC and a change in the biodegradability of DOC produced during the bloom event. The BDOC pool was domi- nated by semi-labile compounds with long turnover times (weeks, months).

\section{MATERIAL AND METHODS}

Experimental design and sampling. Four 5001 cylindrical polycarbonate mesocosms with lids were filled with 4301 water from Lake Esrum, Denmark (Jonasson et al. 1974) and moored in the lake on April 7, 1999. Larger metazoans and other particles were removed with a $100 \mu \mathrm{m}$ net during filling and a diatom bloom was initiated in all enclosures by the addition of inorganic nutrients in approximate Redfield ratios $(52 \mu \mathrm{M}$ $\mathrm{Si}, 30 \mu \mathrm{M} \mathrm{NO}_{3}$, and $2 \mu \mathrm{M} \mathrm{PO}_{4}$ ). Two enclosures were furthermore supplied with $150 \mu \mathrm{M}$ labile organic carbon (glucose). The addition of glucose was part of another experiment investigating microbial ectoenzyme expression and bacterial succession. The glucose addition showed the in situ fate of a 'labile DOC standard' but did not deviate from the nutrient treatment with respect to DOC production. The enclosures with glucose are named 'Nutrients $+C^{\prime}$ ' as opposed to 'Nutrients' for those without glucose. As one 'Nutrients+C' and one 'Nutrients' enclosure partly capsized during a heavy storm over the first night the results from these enclosures are not presented unless specifically stated. From the dilution of the added glucose and nutrients it was calculated that about half the water in the enclosures was replaced with unfiltered lake water. Water temperatures varied between 5.3 and $8.7^{\circ} \mathrm{C}$ over the experimental period of $19 \mathrm{~d}$. A final sample for DOC was taken on Day 21 before the enclosures were dismantled due to increasing wall growth.

Sampling for analyses of abiotic and biotic variables was carried out with clean techniques (gloves, acidwashed polycarbonate bottles) early-morning every second or third day and after thorough mixing of the enclosures with a plastic paddle. In vitro DOC degradation experiments were undertaken 5 times with water from the 2 intact enclosures and covered the pre- bloom, bloom and post-bloom periods. One degradation experiment was carried out in one of the capsized enclosures due to the production of very high concentrations of DOC.

Chemical analyses. Inorganic nutrients were measured in GF/F-filtered water employing standard methods (Anonymous 1985). Limits of detection are: $\mathrm{NO}_{3}: 0.3 \mu \mathrm{M}$, Si: $0.7 \mu \mathrm{M}, \mathrm{PO}_{4}: 0.3 \mu \mathrm{M}$ and $\mathrm{NH}_{4}: 0.2 \mu \mathrm{M}$.

Chlorophyll a (chl a) was measured after acetone extraction and sonication of particles collected on Whatman GF/F filters and the pigments were subsequently separated and detected by high pressure liquid chromatography (Wright et al. 1991). POC and DOC were measured in duplicate independent sam- 
ples from each enclosure. POC was collected on precombusted $13 \mathrm{~mm}$ Whatman GF/F filters, dried at $40^{\circ} \mathrm{C}$ and measured as $\mathrm{CO}_{2}$ after dry combustion at $600^{\circ} \mathrm{C}$ (Søndergaard \& Middelboe 1993). The precision of the POC measurements was within a coefficient of variation between 2 and $3 \%$. Samples for DOC measurements were collected directly in pre-combusted glass tubes added $50 \mu \mathrm{l} 2 \mathrm{~N} \mathrm{HCl}$ and after the $13 \mathrm{~mm} \mathrm{GF} / \mathrm{F}$ filter had been washed with $10 \mathrm{ml}$ sample. DOC was measured by high temperature combustion in a Shimadzu TOC-5000 equiped with an autosampler. The concentrations were calculated from a 4-point calibration curve followed by subtraction of a blank (Milli-Q water). Each run also included - as a quality controla global blank and reference standard supplied by $\mathrm{J}$. Sharp. The coefficients of variation of the individual DOC analyses were always $<2 \%$ and no anomalies with respect to calibration and the level of the blank were present. The machine and our procedures have been tested in 2 international intercalibration exercises. Small bacteria may escape retention by GF/F filters. Previous estimates have shown retention between 80 and $90 \%$ of the total. Thus, only about 3 to $5 \mu \mathrm{M}$ particulate bacterial carbon was included in the DOC samples (Søndergaard \& Middelboe 1993).

Biodegradable DOC measured in vitro. Two different in vitro bioassays were used to estimate the standing pool of BDOC in 2 differently treated enclosures. The Day 1 sample was taken from the capsized 'Nutrients $+C^{\prime}$ enclosure, before we realized the dilution with lake water and then changed to the other enclosure with glucose. Upon return to the laboratory the samples were gravity filtered through GF/F filters within $45 \mathrm{~min}$, and subsequently used to measure BDOC in a bioreactor (sensu Kaplan \& Newbold 1995) and in traditional batch culture incubations (Ogura 1975).

The bioreactor has a bed-volume of $210 \mathrm{ml}$, an approximate residence time of $3 \mathrm{~h}$ and almost perfect plug-flow characteristics, which allows measurement of total BDOC after about $4 \mathrm{~h}$. The reactor consists of a dense biofilm developed on porous glass beads (Shiran) and has been running continuously for $3 \mathrm{yr}$ with feed water from Lake Esrum. The capacity and function of the bioreactor have been tested and described by Søndergaard \& Worm (2000). Briefly, water is pumped once through the reactor at $1 \mathrm{ml} \mathrm{min}^{-1}$ and triplicate samples are routinely collected from the in- and outlet after 5 and $20 \mathrm{~h}$. The decrease in DOC concentration between in- and outlet is defined as total BDOC. The BDOC measured after 5 and $20 \mathrm{~h}$ deviated $<5 \%$, which is equivalent to between 3 and $8 \mu \mathrm{M}$. The mean values for the 2 measurements are presented.

Batch cultures with sampling over time were used to characterise the degradation patterns, the degradation rates and total BDOC. GF/F-filtered samples from 2 enclosures were distributed in 4 burned and acidwashed 0.51 bottles, of which 2 were spiked with inorganic nutrients to provide carbon-limited growth conditions $\left(\mathrm{NO}_{3}\right.$ and $\mathrm{PO}_{4}$ at a final concentration of 12 and $2 \mu \mathrm{M}$, respectively). The bottles were incubated in the dark at room temperature $\left(15\right.$ to $\left.18^{\circ} \mathrm{C}\right)$ and slow shaking. Sampling for total organic carbon $(\mathrm{TOC}=$ no filtration step) was carried out until the endpoint where 2 consecutive measurements did not deviate statistically ( $t$-test, $\mathrm{p}<0.05)$. The endpoint in mineralisation was reached after about 75 to $120 \mathrm{~d}$. Due to the presence of flagellates in the cultures and low community growth yields after 7 to $10 \mathrm{~d}$ of incubation an increase in POC due to bacterial biomass is of minor importance for the measured TOC mineralisation $(<10 \%$; Søndergaard \& Theil-Nielsen 1997). The TOC measurements can be considered a good proxy for DOC.

In our batch culture experiments labile DOC is defined as the amount of DOC removed by bacteria within 7 to $10 \mathrm{~d}$ and the remaining BDOC is called semi-labile. If the degradation rate for the initial 7 to $10 \mathrm{~d}$ remained constant beyond this period, we defined that no labile pool was present. The time courses of DOC mineralisation were used to analyse if the semilabile pool could be characterised by several phases. The number of samples (normally 7 or 8) obviously restricts the precision and level of resolution. We decided (somewhat arbitrarily) that the degradation rates had to separate 2-fold to distinguish different pools. These are called the first, second and third semi-labile pool.

\section{RESULTS}

\section{Chemical and organic environment}

Nitrate and silicate were removed to below the detection limits within 5 to $8 \mathrm{~d}$ (Fig. $1 \mathrm{~A}, \mathrm{~B}$ ), while all systems were phosphate replete with concentrations decreasing from 6 to $3.5 \mu \mathrm{M}$ (data not shown). Ammonium was constantly below $1 \mu \mathrm{M}$ (data not shown). During the development of the bloom the chlorophyll

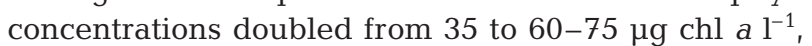
peaked Day 8 and were between 20 and $40 \mu \mathrm{g} \mathrm{chl} \mathrm{a} \mathrm{l^{-1 }}$ when the experiment was terminated Day 19 (Fig. 1C). Microscopic examinations showed total dominance of the diatoms Asterionella, Stephanodiscus, Fragillaria and Cyclotella in all enclosures. Small flagellates and green algae became more abundant during the latter half of the experiment. From Day 8 onwards the diatoms started to aggregate with partial loss of pigments and invasion of bacteria on frustules and aggregates. The POC concentrations increased from $200 \mu \mathrm{M}$ to peak values of about $650 \mu \mathrm{M}$ and started to decrease between Day 8 and 13 (Fig. 1D). Hence, POC peaked 

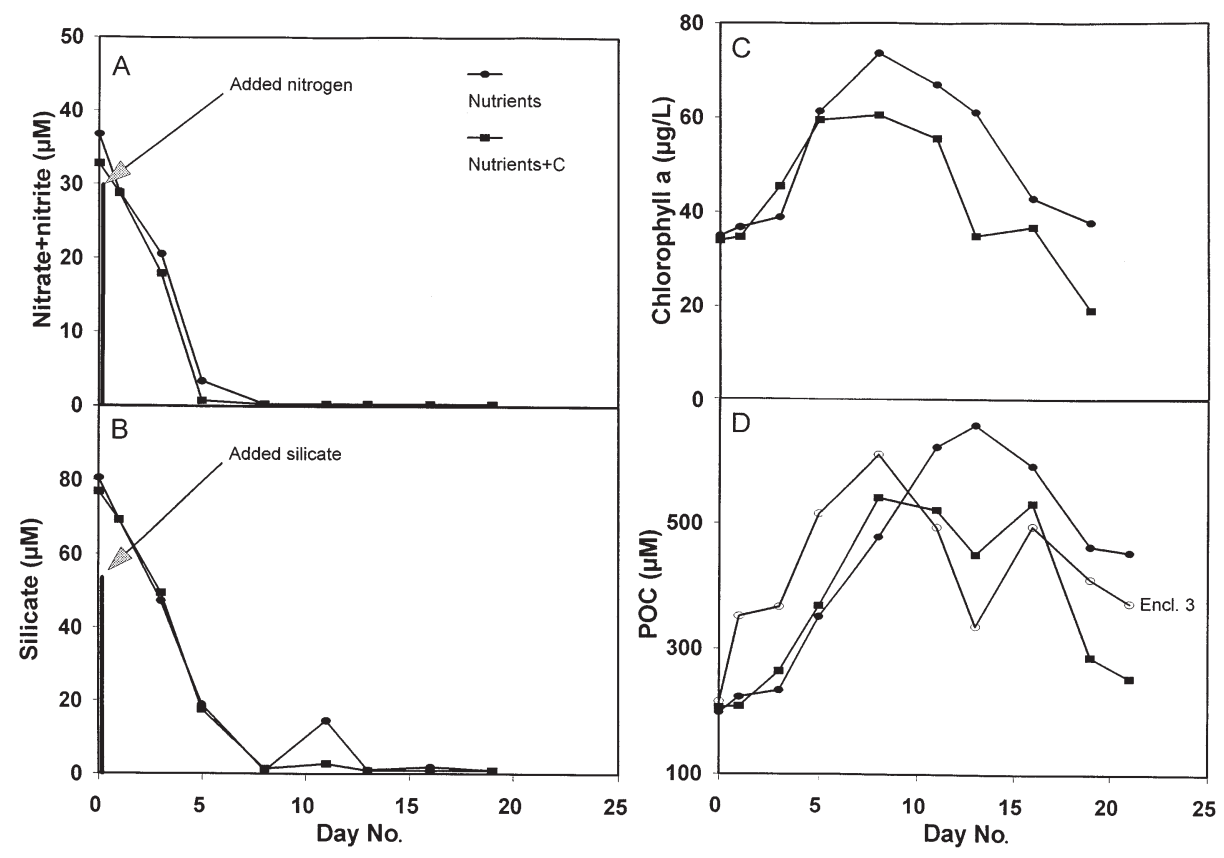

Fig. 1. (A) Concentrations of inorganic nitrogen, (B) silicate, (C) chlorophyll $a$, and (D) particulate organic carbon (POC) in the experimental enclosures. All values in $\mu \mathrm{M}$ elements. The concentrations of added $\mathrm{N}$ and $\mathrm{Si}$ inserted. The POC concentrations for the capsized 'Nutrients+C' enclosure (Encl. 3) are included in (D). The POC values are from Worm et al. (unpubl.) and declined about 5 d later than chlorophyll. In the partly capsized enlosure 'Nutrients+C' (Enclosure 3) the POC peaked Day 8, followed by a major decrease and a recovery from Day 13 to 16 (Fig. 1D). The POC concentrations in Enclosure 3 are included as a very high DOC production took place in this enclosure.

The average DOC concentration in both 'Nutrients' enclosures increased from about 443 to $526 \mu \mathrm{M}$ at an apparent linear rate of $4.4 \mu \mathrm{M} \mathrm{d}^{-1}$ (Fig. 2, $f(x)=443 \pm$ $\left.10+4.35 x \pm 0.46, \mathrm{r}^{2}=0.92, \mathrm{n}=14, \mathrm{p}<0.001\right)$. The glucose addition initially resulted in high DOC concentrations in the 'Nutrients+C' enclosure, but at Day 11 the DOC concentration was not different from the other

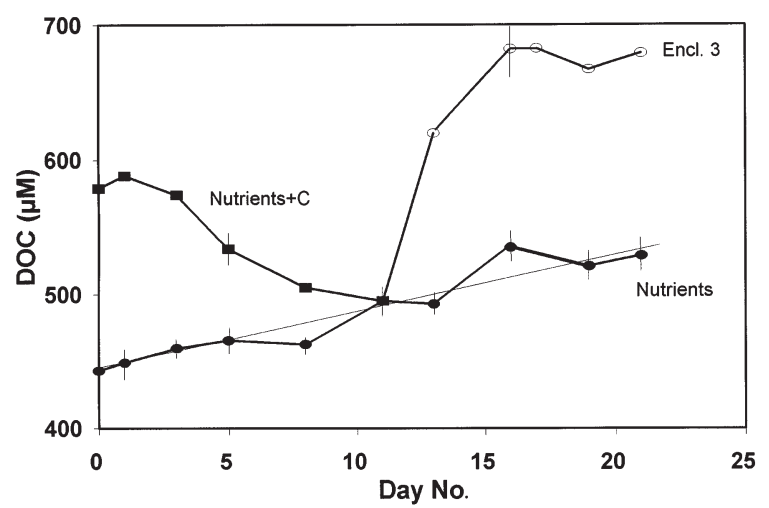

Fig. 2. Concentrations of DOC in the enclosures. Means \pm range of duplicate samples are shown for the 'Nutrients+C' and 1 capsized enclosure (Encl. 3); only range bars outside the markers are shown. Means \pm SD for the 'Nutrients' enclosures include 2 enclosures before Day 11 and then include the 'Nutrients $+C$ ' from Day 11. The regression line for 2 'Nutrients' and 1 'Nutrients+C' enclosures is inserted; $f(x)=443 \pm$ $10+4.35 \mathrm{x} \pm 0.46, \mathrm{r}^{2}=0.92, \mathrm{n}=14$ enclosures. The in situ removal rate of glucose was about $14 \mu \mathrm{M} \mathrm{C} \mathrm{d}{ }^{-1}$ calculated from the decrease in DOC. In one of the partly capsized enclosures (Enclosure 3 with glucose) the DOC increased steeply by $188 \mu \mathrm{M}$ from Days 11 to 16 . The net production of DOC in this enclosure was $234 \mu \mathrm{M}$ as opposed to an average of $83 \pm 7 \mu \mathrm{M}$ in all other enclosures (Fig. 2). The net accumulation of DOC above the initial concentration of $443 \mu \mathrm{M}$ is defined as new bloom-derived DOC.

\section{Biodegradable DOC}

One prerequisite to measure total BDOC and to describe the degradation characteristics of DOC is that carbon is the rate limiting factor. This was tested in the batch cultures. Total BDOC measured with and without the addition of inorganic nutrients was highly correlated and the relationship did not deviate statistically from unity; $f(x)=-8 \pm 8+1.07 x \pm 0.1, \mathrm{r}^{2}=0.94$, $p<0.002$. The only cases where the addition of nutrients increased the degradation rates were when glucose was still present (see 'BDOC degradation kinetics, pool sizes and rates' below). Nutrients were not added to the samples measured in the bioreactor; however, previous experiments with water from Lake Esrum have shown inorganic nutrients always to be present in the outflow (Søndergaard \& Worm 2000) and no nutrient limitations were expected.

The concentrations of total BDOC measured in the batch cultures and in the bioreactor related linearly and were highly significant; $f(x)=5 \pm 17+0.89 x \pm 0.2$, $r^{2}=0.73, p<0.002$ (Fig. 3). On average, the batch incu- 


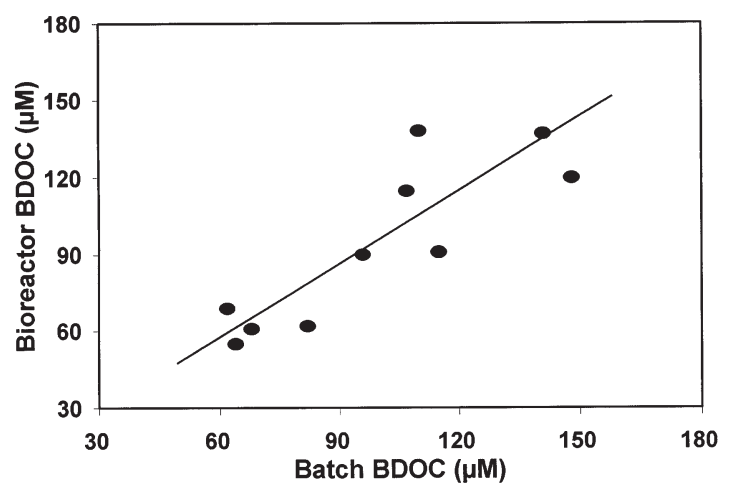

Fig. 3. Comparison of biodegradable DOC (BDOC) measured in a bioreactor and in batch cultures incubated between 135 and $151 \mathrm{~d}$. The calculated regression line is inserted; $f(x)=5 \pm 17+0.89 x \pm 0.2, r^{2}=0.73$

bations had values about $11 \%$ higher than the bioreactor, but not significantly higher. The BDOC values are therefore presented as the means $\pm \mathrm{SD}$ of the 2 methods (Fig. 4).

Despite the net production of DOC at a rate of $4.4 \mathrm{\mu M} \mathrm{d}^{-1}$ the amount of BDOC did not increase in the samples from the 'Nutrients' enclosure until Days 13 and 19 (Fig. 4). The average BDOC was initially $63 \mu \mathrm{M}$, increasing to 72 and $103 \mu \mathrm{M}$ on Days 13 and 19, respectively. The relative degradability was 13 to $15 \%$ of total DOC in the first 4 samples and increased to $22 \%$ on Day 19 (Fig. 4). The concentration of BDOC was higher in the 'Nutrients $+C$ ' than in the 'Nutrients' enclosure. Initially, the difference was due to the added glucose; however, from Day 11, when the glucose signal could no longer be detected, the BDOC in the 'Nutrients $+\mathrm{C}^{\prime}$ enclosure remained higher than in the other enclosure and had by Day 19 increased to $141 \mu \mathrm{M}$ (Fig. 4). The relative amounts of BDOC were 19 and $26 \%$ of total DOC on Days 13 and 19, respectively.

With the assumption that the increase in BDOC above the initial value of $63 \mu \mathrm{M}$ (Fig. 4) only relates to new DOC, it is possible to calculate the distribution of biodegradable and recalcitrant DOC. New DOC is calculated by subtracting the DOC concentration on Day 0 from the concentrations measured on each sampling day $\left(\mathrm{DOC}_{\text {Day }}\right)$. The concentration of new recalcitrant DOC (RDOC) is thus calculated by the formula:

$$
\text { RDOC }=\left(\text { DOC }_{\text {Day }}-443 \mu \mathrm{M}\right)-(\text { BDOC }-63 \mu \mathrm{M})
$$

where BDOC is the values in Fig. 4. With glucose present as a labile DOC source in 1 enclosure we further have to subtract the glucose signal to estimate the production of recalcitrant DOC in the 'Nutrients $+C$ ' enclosure and also to assume that the autochthonous net DOC production was similar in the 2 differently treated enclosures. The concentration of glucose was calculated as the difference

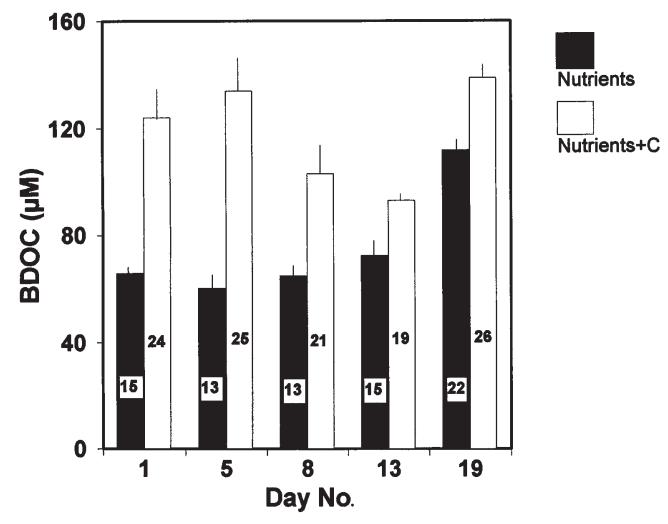

Fig. 4. Concentrations of BDOC in 1 'Nutrients' and 1 'Nutrients $+C^{\prime}$ enclosure. Means \pm SD of measurements from the bioreactor and batch incubations $(n=5)$. The relative values of $\mathrm{BDOC}$ in percentage of total DOC are inserted in each column

between the DOC concentrations in the 2 enclosures $\left(\mathrm{DOC}_{\mathrm{Nu}+\mathrm{C}}-\mathrm{DOC}_{\mathrm{Nu}}\right)$. The concentrations were 72 and 28 $\mu \mathrm{M}$ glucose $\mathrm{C}$ on Days 5 and 8, respectively, and then zero on Day 13. The formula to calculate RDOC in the 'Nutrients $+C$ ' enclosure thus becomes:

$\mathrm{RDOC}=\left(\mathrm{DOC}_{\text {Day }}-443 \mu \mathrm{M}\right)-[\mathrm{BDOC}-(63 \mu \mathrm{M}+$ glucose $)]$

Further, it is possible to calculate the glucose concentration from the results of the degradation experiments if we assume that all glucose was mineralised within 7 to $10 \mathrm{~d}$. The concentration of glucose is the difference in labile DOC between the 2 treatments. By subtracting the amount of labile BDOC measured in the 'Nutrients' enclosure on Days 5 and $8(14 \mu \mathrm{M}$, see 'BDOC degradation kinetics, pool sizes and rates' below) from the labile BDOC measured in 'Nutrients $+C$ ' we get 71 and $27 \mu \mathrm{M}$. Thus, the increases in DOC due to glucose addition perfectly matched the measured increases in labile BDOC.

The calculation with the above formulas showed a production of about $25 \mu \mathrm{M}$ RDOC in both enclosures during the development of the diatom bloom (Fig. 5).

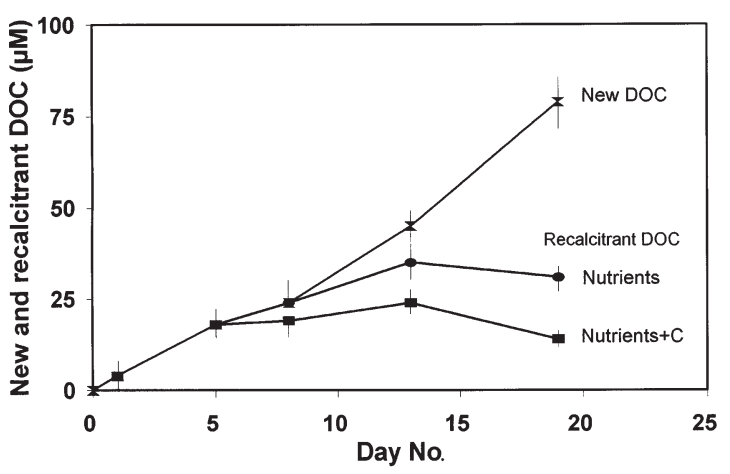

Fig. 5. Concentration of new DOC (means $\pm \mathrm{SD}, \mathrm{n}=3$ ) and the calculated recalcitrant new DOC (means \pm range). Calculations are explained in the text 
From Day 8 there was no further increase in the recalcitrant pools and the new DOC produced during the decay of the bloom was apparently biodegradable. A small decrease in the RDOC pool was observed for the 'Nutrients+C' enclosure. However, the uncertainties in the calculations warrant caution when interpreting rather small changes in recalcitrance. During our final sampling, between 60 and $82 \%$ of the new DOC was biodegradable (Fig. 5).

We did not follow the biodegradability of DOC in the capsized Enclosure 3. When we detected the high DOC concentrations, the BDOC was measured in duplicate batch cultures in a sample collected on Day 19. Of the $677 \mu \mathrm{M}$ total DOC, $95 \mu \mathrm{M}(14 \%)$ was degraded over $135 \mathrm{~d}$ and it was calculated that about $15 \%$ of the new DOC was biodegradable. Hence, a highly recalcitrant DOC had been produced by the plankton community in this enclosure and with respect to degradability the new DOC resembled the DOC present when the experiment was initiated.

\section{BDOC degradation kinetics, pool sizes and rates}

The time courses of DOC mineralisation in the batch cultures are exemplified by samples collected on Days 1, 5, 13 and 19. One sample with a glucose signal is included ('Nutrients $+C^{\prime}$ ', Day 5). Identical time courses were found for the samples taken from the 'Nutrients' enclosure on Days 1, 5 and 8. The results showed a labile organic pool at about $14 \mu \mathrm{M}$ and 2 phases for the semi-labile pool (Fig. 6). Although the size of the labile pool due to the presence of glucose was much higher in the 'Nutrients+C'

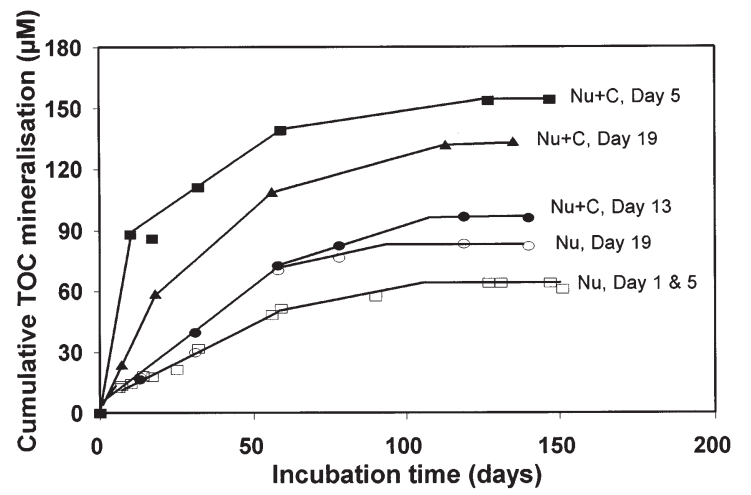

Fig. 6. Cumulative TOC mineralisation in batch cultures. Samples were collected at the indicated days in the 'Nutrients $+C$ ' and 'Nutrients' enclosures. The lines are drawn after the procedure described in the 'Material and methods'. The values for 'Nutrients $+C$ ' on Day 5 are from the decomposition experiment added inorganic nutrients; all other values are means of duplicate DOC analyses from duplicate bottles with and without addition of inorganic nutrients enclosure, similar kinetics as in the 'Nutrients' enclosure were found for the samples collected on Days 1, 5 and 8. Day 13 both enclosures had almost identical initial degradation rates, which remained constant during $56 \mathrm{~d}$ of incubation. No labile pool was by our definition present (Fig. 6). Similarly, no labile pool was present in the samples collected on Day 19, as the initial phase with constant degradation rates lasted about 20 d. Except for the samples with glucose the BDOC pool was dominated by semi-labile compounds accounting for 80 to $100 \%$ of the total (Fig. 7).

The DOC degradation in samples from the 'Nutrients $+C^{\prime}$ enclosure showed the expected high initial rates (from 5.7 to $10 \mu \mathrm{M} \mathrm{d}^{-1}$ ) as long as glucose was present (Fig. 8). Much lower rates were found in those samples not added an extra supply of inorganic nutrients (Fig. 8), but identical amounts of total BDOC were measured in both cases. In the 'Nutrients' enclosure the labile DOC was utilised at rates close to $2 \mu \mathrm{M} \mathrm{d}^{-1}$ (Fig. 8). No labile pool was identifiable on Day 13 and the initial degradation rate had decreased to about $1 \mu \mathrm{M} \mathrm{d}^{-1}$ in both enclosures. However, by Day 19 the degradation rate for the first semi-labile pool increased to 2 and $3 \mu \mathrm{M} \mathrm{d}^{-1}$ in the 'Nutrients' and 'Nutrients+C', respectively.

The results from the batch culture experiments allowed turnover times for the different BDOC pools to be calculated and the time needed to measure total BDOC to be identified. By definition the turnover time for labile DOC is 7 to $10 \mathrm{~d}$, while the different semilabile pools had turnover times between 18 and $80 \mathrm{~d}$ (Table 1). The time used to reach the no further measurable mineralisation ranged from 75 to $120 \mathrm{~d}$.

\section{DISCUSSION}

\section{Production and accumulation of DOC}

Most studies on the accumulation of autochthonous DOC have been carried out in marine systems, where accumulation over the productive season (Carlson et al. 1994, Williams 1995, Børsheim \& Myklestad 1997) and in connection with both in situ (Ittekkot et al. 1981, Billen \& Fontigny 1987) and experimental phytoplankton blooms (Norrman et al. 1995, Fajon et al. 1999, Søndergaard et al. 2000) have solid empirical documentation. However, the magnitude and duration of events are variable in different environments and experimental conditions. The in situ accumulation of autochthonous DOC recorded over seasonal time scales ranges from a low of about $0.1 \mu \mathrm{M} \mathrm{d}^{-1}$ in the Sargasso Sea (Carlson et al. 1994), $0.2 \mu \mathrm{M} \mathrm{d}^{-1}$ in the Norwegian Sea (Børsheim \& Myklestad 1997) to $3 \mu \mathrm{M} \mathrm{d}^{-1}$ in the North Sea (Williams 1995). 


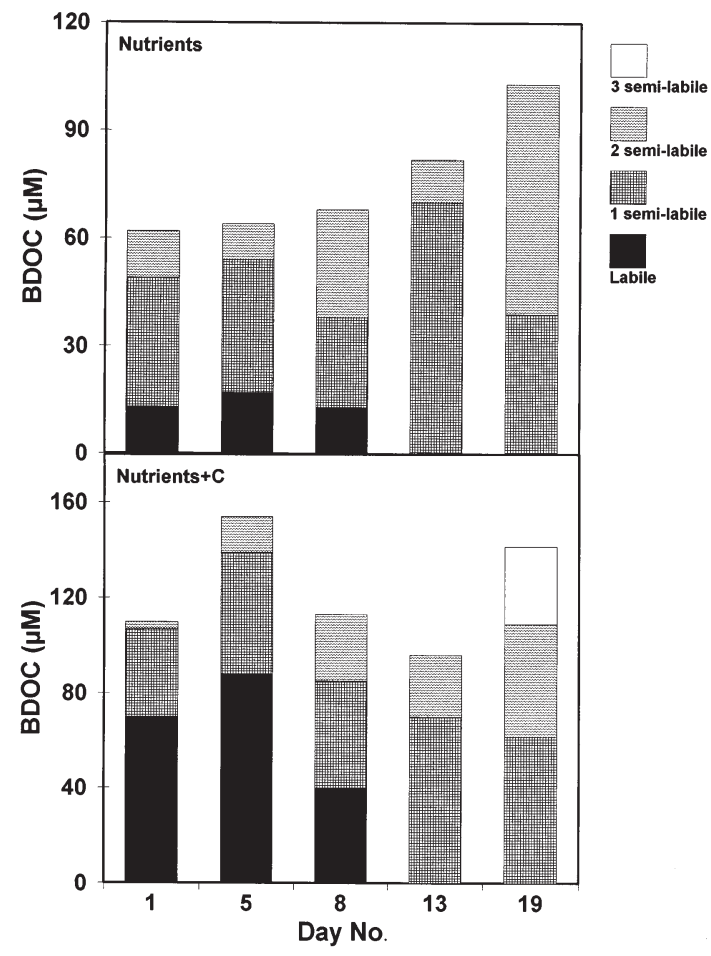

Fig. 7. Sizes of the BDOC pools presented with respect to degradability. Values from Fig. 6

Temporal increases in DOC have also been observed in lakes (Allen 1969, Ochiai et al. 1979, Søndergaard \& Schierup 1982, Søndergaard et al. 1995), but only a few examples can be compared with the present study due to the possibility of terrestrial and littoral influx. One such example is the net production of $9 \mu \mathrm{M} \mathrm{d}^{-1}$ over $25 \mathrm{~d}$ during the decline of a diatom spring bloom in the eutrophic lake Frederiksborg Slotssø (Søndergaard et al. 1995). Another example is from the eutrophic Japanese Lake Nakanuma. During a spring

Table 1. Turnover times ( $T$ in d) for the different pools of biodegradable DOC (BDOC). $T_{\mathrm{L}}$ is labile DOC and the numeric labelling signifies the first, second and third semi-labile pools. The time needed to reach the endpoints (d) for total $\mathrm{BDOC}$ measurements is also presented

\begin{tabular}{|lrrrrr|}
\hline Time/pools & April 8 & April 12 & April 15 & April 20 & April 26 \\
\hline 'Nutrients' enclosure & & & & & \\
$T_{\mathrm{L}}$ & 7 & 10 & 7 & - & - \\
$T_{1}$ & 50 & 50 & 21 & 58 & 18 \\
$T_{2}$ & 53 & 53 & 52 & 54 & 57 \\
Endpoint (d) & 110 & 113 & 80 & 112 & 75 \\
‘Nutrients+C' enclosure & & & & & \\
$T_{\mathrm{L}}$ & 7 & 10 & 7 & - & - \\
$T_{1}$ & 80 & 46 & 33 & 58 & 18 \\
$T_{2}$ & 33 & 60 & 60 & 61 & 38 \\
$T_{3}$ & & & & & 57 \\
Endpoint (d) & 120 & 116 & 100 & 119 & 113 \\
\hline
\end{tabular}

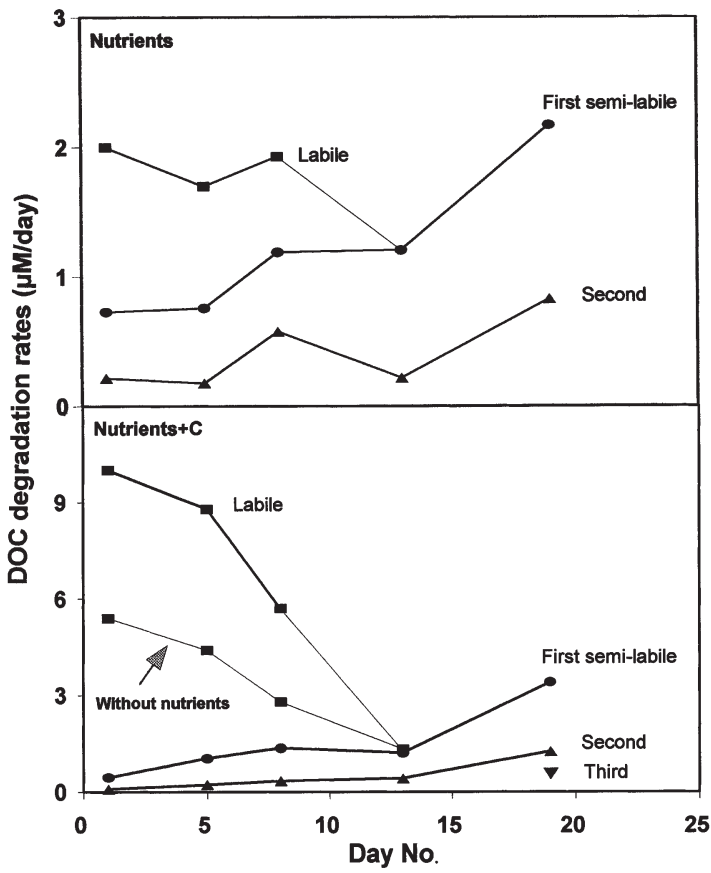

Fig. 8. Degradation rates of the BDOC pools identified in Fig. 7. The degradation rates of labile DOC in samples from the 'Nutrients+C' enclosure are shown for the batch culture experiments with and without the addition of inorganic nutrients

bloom a constant net production of DOC occurred at a rate of $2.8 \mu \mathrm{M} \mathrm{d}^{-1}$ over $45 \mathrm{~d}$ (Ochiai et al. 1979). Peak DOC concentrations co-occurring with the peak diatom bloom in Lake Constance are also indicative of the production of new DOC (Weiss \& Simon 1999).

We observed that DOC increased at an almost constant rate of $4.4 \mu \mathrm{M} \mathrm{d}^{-1}$ in 3 out of 4 enclosures. To the best of our knowledge this is the first unequivocally experimental demonstration of the accumulation of autochthonous DOC in freshwater. The result confirms, as suggested by Søndergaard et al. (2000), that DOC accumulation is a common feature that can take place in all sequences of a phytoplankton bloom and not only during the decay and sedimentation of nutrient deficient plankton communities. One enclosure deviated, however, and had a very high net DOC production of $188 \mu \mathrm{M}$ in $5 \mathrm{~d}$ and the standing stock of DOC increased by $65 \%$ over the course of the experiment (Fig. 2). The accumulation of DOC co-occurred with a steep decline of $158 \mu \mathrm{M}$ in POC from Days 11 to 13 followed by a net production of $160 \mu \mathrm{M}$ POC (Fig. 1D). Thus, a mass balance of organic carbon was present if the DOC was pro- 
duced by particle dissolution with a low respiratory loss and if $30 \mu \mathrm{M}$ DOC accumulated together with the net POC production from Days 13 to 16 . Organic carbon partitioning with very high DOC values has previously been found (Carlson et al. 1998, Søndergaard et al. 2000). This leaves us to explain such an event in 1 of 4 enclosures. The 'Nutrients $+\mathrm{C}$ ' enclosure with the high DOC production was re-inoculated with unfiltered lake water during a storm, but so was one 'Nutrients' enclosure that behaved 'normally'. The high DOC production occurred in a 'Nutrients+C' enclosure - although half the glucose was lost - but glucose was also added to another 'normal' enclosure. No obvious and major differences in the plankton communities were found among the 4 enclosures. Thus, no further interpretations can be presented and the observation only adds to previous records of high DOC production in episodic events.

High net production of DOC and specifically of polymeric carbohydrates is a known phenomenon in nutrient deficient algal communities and can be exemplified by the $15 \mu \mathrm{M} \mathrm{d}^{-1}$ recorded during the decay of a Phaeocystis pouchetii bloom in coastal waters (Billen \& Fontigny 1987). A very high rate of about $40 \mu \mathrm{M} \mathrm{d}^{-1}$ was found by Norrman et al. (1995) during the decay and sedimentation of an experimental diatom bloom. The latter value is comparable in magnitude to the DOC accumulation rate in the present study. Although we can not present a mechanistic explanation for the burst production of DOC, the results support the view that episodic events with very high DOC production during nutrient deficiency and decay of diatom blooms can be an important DOC producing process. In accord with Norrman et al. (1995) and Fajon et al. (1999) we suggest organic excretion of extracellular polymeric substances and algal lysis as the most plausible explanations to account for the fast transformation of particulate matter to a dissolved form.

\section{Biodegradability of DOC}

Accumulation of DOC can only take place if the rate of production is higher than the rate of removal. Bacterial degradation is believed to be the most important process controlling DOC removal, possibly aided by photochemical transformations (Williams 2000). Accumulation of DOC therefore is interpreted as a temporal uncoupling between DOC production and bacterial assimilation. The mechanistic explanations are that inorganic nutrients can limit the bacterial uptake capacity of otherwise biodegradable DOC or, alternatively, but not exclusively, that a part of the produced DOC escapes fast degradation due to high biochemical resistance (Thingstad \& Lignell 1997). Labile sub- strates like amino acids and monosaccharides have low concentrations and fast turnover times (Fuhrman \& Ferguson 1986, Jørgensen \& Jensen 1994) so a change in BDOC is most likely explained by an increased production of semi-labile DOC, which accumulates until a new equilibrium between production and consumption is reached. The hypothesis is supported by several studies presenting evidence for the semi-labile nature of newly produced DOC (Ochiai et al. 1979, Billen \& Fontigny 1987, Fry et al. 1996, Søndergaard et al. 2000).

We have no means to explore changes in the degradability of 'old' DOC present in the enclosures when the study was initiated. The used methodology only reveals any net changes in BDOC, which then can be compared with the DOC concentration in each sample. Accordingly, the term new DOC is operational and defined as an increase in DOC concentration. For oceans the comparison is the low DOC concentration in deep waters (Carlson et al. 1994) and in our study it was the Day 0 concentration. In the comparison of BDOC with DOC we assumed that the initial BDOC concentration of about $63 \mu \mathrm{M}$ was a 'steady state' value, and that any deviation from this value could be related to the net increase in DOC. Although the assumption cannot be tested, it is supported by other studies. Norrman et al. (1995) in an elegant study with stabile isotopes have shown that bacteria selectively used new DOC produced during the decay of a diatom bloom as opposed to older DOC. However, the selectivity is not absolute as bacteria often assimilate a mixture of 'new' and 'old' DOC (Cherrier et al. 1999).

During the exponential growth phase of the bloom, the DOC concentration increased by 25 to $30 \mu \mathrm{M}$ without an increase in BDOC. The accumulating DOC was apparently recalcitrant. Although DOC continued to accumulate in the enclosures, an increasing fraction of the DOC became biodegradable. When we initiated the study, the relative fraction of BDOC was $15 \%$ of total DOC which comply with a review of the literature (Søndergaard \& Middelboe 1995) and most recent studies (Tranvik \& Jørgensen 1995, Weiss \& Simon 1999, Søndergaard \& Worm 2000). However, the relative $\mathrm{BDOC}$ fraction increased to between 22 and $26 \%$ in the samples collected on Day 19. If we assume preferential use of new DOC, between 60 and $82 \%$ of the new DOC was biodegradable on Day 19 as opposed to zero on Days 5 and 8 and between 21 and $48 \%$ on Day 13 (Fig. 5). A higher degradability was always found in the 'Nutrients $+C$ ' enclosure, but as none of the added glucose was present Days 13 and 19 we have no evidence for co- metabolism, where a labile carbon and energy source can mediate the degradation of otherwise recalcitrant compounds (Brophy \& Carlson 1989). 
The change in DOC degradability over the course of the bloom could have several explanations, among these the production of different products and/or a change in the physiological ability of the batch culture inocula to utilize a larger fraction of the DOC pool as a function of the bloom development. Photochemical reactions and specifically UV radiation can alter recalcitrant DOC to biodegradable DOC and vice versa (Moran \& Zepp 1997, Benner \& Biddanda 1998). However, this possibility can be excluded as the used polycarbonate enclosures and the lids have an approximate $100 \%$ absorption cut off below $400 \mathrm{~nm}$.

We have circumstantial evidence to suggest that a change in the DOC quality can explain the observed change in degradability. The BDOC was measured with 2 different bioassays, which showed a quantitative agreement (Fig. 3). While the function of the bioreactor is based on the high physiological diversity and high capacity of a heterotrophic biofilm matured over 3 yr (Kaplan \& Newbold 1995), the batch incubations rely on the inoculum, the succession of bacteria, and organic recycling taking place during the course of the incubations. Although some of the decomposition in the batch cultures most probably takes place in a biofilm on the bottle walls, it is hard to envisage that the bacterial communities developing in the simple bacteria/flagellate system in the bottles are identical to the complex biofilm in the reactor. However, the quantitative agreement between the 2 assays indicates that the hydrolytic capacities were similar. During the decay of the bloom we might expect that the inoculum for the batch cultures changed toward a dominance of the Cytophaga-Flavobacter cluster, which has a high capacity to decompose complex mucopolysaccharides and other polymeric substances (Riemann et al. 2000). This could be an argument for the change to higher BDOC values. However, degradation of complex substrates seems not to require a bacterial succession (Janse et al. 2000) and most likely all bacterial groups were present in the inoculum at all times. Further, it seems unlikely that the bioreactor community should change from an inability to degrade new DOC in samples collected on Day 8 to a higher capacity on Day 19 if the quality of the DOC was the same those 2 days. Between runs the bioreactor was maintained with filtered lake water.

Microbial communities can transform labile DOC to recalcitrant products (Brophy \& Carlson 1989) and bacteria produce highly resistant capsular and peptidoglycan cell wall material (McCarthy et al. 1998, Stoderegger \& Herndl 1998). Such DOC production/ transformations could have taken place both in situ and in our bioassays and increased the RDOC pool. However, it seems highly unlikely that these processes should have ceased after Day 8 when the production of
RDOC ceased. The simplest explanation supported by our results therefore is that the change in biodegradability was caused by a change in the quality of DOC.

Production of recalcitrant DOC during experimental algal blooms has previously been reported. Fry et al. (1996) worked with samples taken about $7 \mathrm{~d}$ after a diatom bloom and exposed the newly produced DOC (about $100 \mu \mathrm{M}$ ) to bacterial degradation in the dark. After 2.5 yr about 25 to $30 \%$ of the new DOC remained and could be characterized as recalcitrant. In a study by Meon \& Kirchman (unpubl.) they darkened their enclosures at the peak of a massive diatom bloom, where DOC had increased by $34 \%$ in the experiment added nutrients. About $25 \%$ of the bloom-derived DOC remained after about $4 \mathrm{wk}$ in the dark and were considered semi-labile or recalcitrant. This fraction of the DOC was enriched in dissolved combined amino acids (DCAA) and especially non-protein amino acids, which are suggested to play an important role in the formation of recalcitrant material. In contrast, the bloom-derived DOC in the control enclosure was not enriched in DCAA and was fully decomposed during the dark period (Meon \& Kirchman unpubl.). It is not possible to identify when the recalcitrant DOC was produced in the studies by Fry et al. (1996) and Meon \& Kirchman (unpubl.). Theoretically, microbial transformations and/or production of recalcitrant compounds could have taken place during algal growth or during the decomposition sequence. We argue that the quantitative agreement between the measurements of BDOC in the bioreactor and the batch incubations suggests a bloom-dependent sequence in the production of DOC with different qualities.

The above analysis leaves us with an unexplained high net DOC production and low degradability in the partly capsized enclosure with added glucose. Only $15 \%$ of the new DOC collected on Day 19 could be degraded over $135 \mathrm{~d}$. The recalcitrant nature of this new DOC is remarkable. If such events are frequently occurring, a large fraction of the recalcitrant DOC in aquatic systems might be of autochthonous origin and produced by the plankton.

\section{Labile and semi-labile DOC}

The decomposition experiments showed that it was not possible to quantify BDOC in short-term batch culture incubations. Less than half of the mineralisation was detected within a time frame of 2 wk (Fig. 6). A similar conclusion was reached by Søndergaard et al. (2000) working with the degradation of new DOC produced in marine mesocosms. They showed that the turnover time of new DOC, partly dominated by polysaccharides, was at least 3 to 4 wk. Furthermore, long 
turnover times of new DOC can be extracted from the results presented by Ochiai et al. (1979). The turnover time for accumulated combined polysaccharides produced during a natural phytoplankton bloom was about $20 \mathrm{~d}$.

Decomposition of DOC in batch cultures is a measure of potential rates and turnover times and can not directly be translated to in situ conditions. However, it has been shown that bacterial densities and activity reached in batch cultures after a few days are comparable to those in situ (Søndergaard \& Middelboe 1995). The continued succession and metabolism of bacteria under carbon-limited growth conditions must after a few days depend on less easily available DOC and the recycling products released by bacteria and via flagellate grazing. We therefore suggest using batch experiments to reveal the correct kinetics, which produce rates of the same magnitude as in situ. The conclusion is that semi-labile DOC with long turnover times (weeks, months) was dominating the standing pool of DOC. While labile DOC averaged $14 \mu \mathrm{M}$, semi-labile DOC could explain the remaining $50 \mu \mathrm{M}$ BDOC on Days 1, 5 and 8 (Fig. 7, Table 1). Likewise, the biodegradable organic compounds causing the net increase in DOC after Day 8 needed long turnover times; otherwise DOC would not accumulate. Further, inorganic nutrients did not affect the outcome of the experiments, so we suggest it was the biochemical resistance to microbial hydrolysis that controlled the degradation rate. The possibility cannot be excluded that small pools of labile DOC were present on Days 13 and 19; however, they could not be detected due to the large pools of semi-labile DOC decomposing at rates not very different from labile DOC (Fig. 8).

Many recent studies on the biodegradability of DOC have been carried out with short-term batch culture incubations lasting less than 10 to $14 \mathrm{~d}$ (Søndergaard 1984, Søndergaard et al. 1995, Tranvik \& Jørgensen 1995, Carlson \& Ducklow 1996, Weiss \& Simon 1999). The amount of BDOC is most often identified as a plateau level in bacterial numbers and biomass reached after a few days of incubation (Søndergaard \& Middelboe 1995, Weiss \& Simon 1999). It is rather rare to find studies identifying the plateau level in DOC removal as done by Ogura (1975), Chen \& Wangersky (1996) and Fry et al. (1996). The quantitative biases of short-term incubations are not known, but the results suggest recommending long incubation times and using DOC and/or respiration to identify when mineralisation ceases. The bioreactor method can be used to measure BDOC within a few hours. This is an attractive alternative to prolonged batch incubations.

We have shown that the biodegradable fraction of DOC in this eutrophic clear water lake is dominated by semi-labile components. Furthermore, new DOC pro- duced during different sequences of a diatom bloom can have a variable degradability, ranging from apparent recalcitrant to almost $100 \%$ biodegradable, albeit at low rates. The change in DOC quality was confirmed by 2 independent bioassays. The scientific community studying DOC is currently faced with the problem of explaining the causes and mechanisms of the very different quantities and qualities of DOC produced during bloom events. The combined use of batch cultures and a bioreactor may help to answer some of the remaining questions.

Acknowledgements. This study was supported by the Danish Natural Science Research Council (No. 9601319), the Carlsberg Foundation, and the EU 4th Framework Programme (contract: ENV4-CT97-0570-PL97-1027). We acknowledge the assistance by Nils Willumsen and Anne J. Jacobsen and further the close cooperation with and help from Jakob Worm and Lasse Riemann. We thank Meinhard Simon and 4 anonymous referees for constructive suggestions.

\section{LITERATURE CITED}

Allen HL (1969) Chemo-organotrophic utilization of dissolved organic compounds by planktonic bacteria and algae in a pond. Int Rev Ges Hydrobiol 54:1-33

Anonymous (1985) Limnological methods. Akademisk Forlag, Copenhagen

Benner R, Biddanda B (1998) Photochemical transformations of surface and deep marine dissolved organic matter: effects on bacterial growth. Limnol Oceanogr 43:1373-1378

Billen G, Fontigny A (1987) Dynamics of a Phaeocystis-dominated bloom in Belgian coastal waters. II. Bacterioplankton dynamics. Mar Ecol Prog Ser 37:249-257

Birge EA, Juday C (1934) Particulate and dissolved organic matter in inland lakes. Ecol Monogr 4:440-474

Børsheim KY, Myklestad SM (1997) Dynamics of DOC in the Norwegian Sea inferred from monthly profiles collected during 3 years at $66^{\circ} \mathrm{N}, 2^{\circ}$ E. Deep-Sea Res 44:593-601

Brophy JE, Carlson DJ (1989) Production of biologically refractory dissolved organic carbon by natural seawater populations. Deep-Sea Res 36:497-507

Carlson CA, Ducklow HW (1996) Growth of bacterioplankton and consumption of dissolved organic carbon in the Sargasso Sea. Aquat Microb Ecol 10:69-85

Carlson CA, Ducklow HW, Michaels AF (1994) Annual flux of dissolved organic carbon from the euphotic zone in the northwestern Sargasso Sea. Nature 371: 405-408

Carlson CA, Ducklow HW, Hansell DA, Smith WO Jr (1998) Organic carbon partitioning during spring phytoplankton blooms in the Ross Sea polynya and the Sargasso Sea. Limnol Oceanogr 43:375-386

Chen W, Wangersky PJ (1996) Rates of microbial degradation of dissolved organic carbon from phytoplankton cultures. J Plankton Res 18:1521-1533

Cherrier J, Bauer JE, Druffel ERM, Coffin RB, Chanton JP (1999) Radiocarbon in marine bacteria: evidence for the age of assimilated carbon. Limnol Oceanogr 44:730-736

Eberlein K, Brockmann UH, Hammer KD, Kattner G, Laake M (1983) Total dissolved carbohydrates in an enclosure experiment with unialgal Skeletonema costatum culture. Mar Ecol Prog Ser 14:45-58 
Fajon C, Cauwet G, Lebaron P, Terzic S, Ahel M, Malej A, Mozetic P, Turk V (1999) Accumulation of polysaccharides in planktonic cells, its excretion and bacterial response during a controlled experiment. FEMS Microbiol Ecol 29: 351-363

Fry B, Hopkinson CS Jr, Nolin A, Norrman B, Zweifel UL (1996) Long-term decomposition of DOC from experimental diatom blooms. Limnol Oceanogr 41:1344-1347

Fuhrman JA, Ferguson RL (1986) Nanomolar concentration and rapid turnover of dissolved free amino acids in seawater: agreement between chemical and microbiological measurements. Mar Ecol Prog Ser 33:237-242

Ittekkot V, Brockmann U, Michaelis W, Degens ET (1981) Dissolved free and combined carbohydrates during a phytoplankton bloom in the northern North Sea. Mar Ecol Prog Ser 4:299-305

Janse I, Zwart G, van der Maarel MJEC, Gottschall JC (2000) Composition of the bacterial community degrading Phaeocystis mucopolysaccharides in enrichment cultures. Aquat Microb Ecol 22:119-133

Jonasson PM, Lastein E, Rebsdorf A (1974) Production, insolation, and nutrient budget of eutrophic Lake Esrom. Oikos 25:255-277

Jørgensen NOG, Jensen RG (1994) Microbial fluxes of free monosaccharides and total carbohydrates in freshwater determined by PAD-HPLC. FEMS Microbiol Ecol 14:79-94

Kaplan LA, Newbold JD (1995) Measurement of stream biodegradable dissolved organic carbon with a plug-flow bioreactor. Water Res 29:2696-2706

McCarthy MD, Hedges JI, Benner R (1998) Major bacterial contribution to marine dissolved organic nitrogen. Science 281:231-234

Moran MA, Zepp RG (1997) Role of photoreactions in the formation of biologically labile compounds from dissolved organic matter. Limnol Oceanogr 42:1307-1316

Norrman B, Zweifel UL, Hopkinson CS Jr, Fry B (1995) Production and utilization of dissolved organic carbon during an experimental diatom bloom. Limnol Oceanogr 40:898-907

Ochiai M, Nakajima T, Hanya T (1979) Seasonal fluctuation of dissolved organic matter in Lake Nakanuma. Jpn J Limnol 40:185-190 (in Japanese)

Ogura N (1975) Further studies on decomposition of dissolved organic matter in coastal seawater. Mar Biol 31:101-111

Riemann L, Steward GF, Azam F (2000) Dynamics of bacterial community composition and activity during a mesocosm diatom bloom. Appl Environ Microbiol 66:578-587

Sharp JH (1973) Size classes of organic carbon in seawater. Limnol Oceanogr 18:441-447

Søndergaard M (1984) Dissolved organic carbon in Danish lakes: concentration, composition and lability. Verh Int Ver Angew Theor Limnol 22:780-784

Editorial responsibility: Fereidoun Rassoulzadegan, Villefranche-sur-Mer, France
Søndergaard M, Borch NH (1992) Decomposition of dissolved organic carbon (DOC) in lakes. Erg Limnol 37:9-20

Søndergaard M, Middelboe M (1993) Measurement of particulate organic carbon: a note on the use of glass fiber (GF/F) and Anodisc filters. Arch Hydrobiol 127:73-85

Søndergaard M, Middelboe M (1995) A cross-system review of labile dissolved organic carbon. Mar Ecol Prog Ser 118: 283-294

Søndergaard M, Schierup HH (1982) Dissolved organic carbon during a spring diatom bloom in Lake Mossø, Denmark. Water Res 16:815-821

Søndergaard M, Theil-Nielsen J (1997) Bacterial growth efficiency in lakewater cultures. Aquat Microb Ecol 12: 115-122

Søndergaard M, Worm J (2000) Measurement of biodegradable dissolved organic carbon (DOC) in lake water with a bioreactor. Water Res (in press)

Søndergaard M, Hansen B, Markager S (1995) Dynamics of dissolved organic carbon lability in a eutrophic lake. Limnol Oceanogr 40:46-54

Søndergaard M, Williams PJleB, Cauwet G, Riemann B, Robinson C, Terzic S, Woodward EMS, Worm J (2000) Net accumulation and flux of DOC and DON in marine plankton communities. Limnol Oceanogr 45:1097-1111

Stoderegger K, Herndl GJ (1998) Production and release of bacterial capsular material and its subsequent utilization by marine bacterioplankton. Limnol Oceanogr 43:877-884

Thingstad F, Lignell R (1997) Theoretical models for the control of bacterial growth rate, abundance, diversity and carbon demand. Aquat Microb Ecol 13:19-27

Tranvik LJ, Jørgensen NOG (1995) Colloidal and dissolved organic matter in lake water: carbohydrate and amino acid composition, and ability to support bacterial growth. Biogeochemistry 30:77-97

Weiss M, Simon M (1999) Consumption of labile dissolved organic matter by limnetic bacterioplankton: the relative significance of amino acids and carbohydrates. Aquat Microb Ecol 17:1-12

Williams PJleB (1995) Evidence for the seasonal accumulation of carbon-rich dissolved organic material, its scale in comparison with changes in particulate material and the consequential effect on net $\mathrm{C} / \mathrm{N}$ assimilation ratios. Mar Chem 51:17-29

Williams PJleB (2000) Heterotrophic bacteria and the dynamics of dissolved organic material. In: Kirchman DL (ed) Microbial ecology of the oceans. Wiley-Liss, New York, p 153-200

Wright SA, Jeffrey SW, Mantoura RFC, Llewelly CA, Blörnland T, Repeta D, Welschmeyer N (1991) Improved HPLC method for the analysis of chlorophylls and carotenoids from marine phytoplankton. Mar Ecol Prog Ser 77 : 183-196

Submitted: March 31, 2000; Accepted: October 27, 2000 Proofs received from author(s): November 20, 2000 